SYMPOSIUM ON CIRCUMCISION

\title{
Circumcision: a surgeon's perspective
}

\author{
J M Hutson
}

J Med Ethics 2004;30:238-240. doi: 10.1136/jme.2003.001313

$\mathrm{T}$ he foreskin in small boys causes much anxiety in our society. It develops during the second half of gestation, and in premature infants may appear relatively deficient. By term, however, it has grown and protruded to well beyond the glans penis. The inner layer of the foreskin is densely adherent to the surface of the glans and cannot be retracted until it is fully separated, which occurs during the first few years of life. Prior to that time the distal opening of the foreskin is narrow, but because of its adherence there is no significant pocket under the skin to allow accumulation of urine or debris. Later in childhood, after the foreskin is fully separated, urine and dirt can accumulate between the foreskin and the glans, leading to infection and inflammation (balanitis). With recurrent balanitis, and/or tearing of the delicate foreskin, phimosis or scarring may constrict the distal foreskin.

Circumcision has a long history in ancient societies of the Middle East, and is likely to have arisen as an early public health measure for preventing recurrent balanitis, caused by sand accumulating under the foreskin. Circumcision is a major part of the ritual for such religions as Judaism, Christianity, and Islam, and it is probably no accident that all of these arose in the Middle East. By contrast, in religions arising outside the arid Middle East (Hinduism, Shintoism, Buddhism), there is no ritual circumcision. In aboriginal society in Australia, circumcision is practised also.

The importance of preventing recurrent balanitis and secondary phimosis in arid, sandy regions was confirmed by the Australian army medical corps in two world wars. During both wars, Australian soldiers were stationed in North Africa and the Middle East, and the incidence of recurrent balanitis caused by sand under the foreskin reached "epidemic" proportions, leading to large numbers of soldiers requiring circumcision (A M Hutson, personal communication, 1974). Because circumcision in an adult is a major procedure, routine neonatal circumcision became standard following the second world war. In babies, circumcision is a much simpler and less dangerous operation than in adults, but it is still not without its problems, as will be seen below.

In developed countries, the incidence of circumcision varies considerably, with western European countries having quite a low incidence of circumcision compared with USA and Australia. ${ }^{1-5}$ In the USA, circumcision is still extremely common, related to the desires of both fundamentalist Christian and Jewish sectors in the community. ${ }^{6}$ There is a widely held perception in the USA that circumcision is required for "hygiene", although there is no need to regularly wash under the foreskin until later in childhood. In Australia, by contrast, the incidence of circumcision has been falling progressively since the 1970s, in response to the high incidence of complications of the procedure that was seen in the 1960s and the 1970s. ${ }^{4}$

Neonatal circumcision requires adequate analgesia by a local anaesthetic technique, such as dorsal penile nerve block, a local ring penile block or local anaesthetic cream. ${ }^{6}$ The Plastibell device or Gomco clamp is used in the neonatal period. ${ }^{7}$ By contrast, circumcision in older children is usually done under general anaesthesia with a regional block such as an injection into the sacral spinal canal. In children, the procedure is done with standard surgical techniques with excision of the skin with a scalpel or scissors, adequate control of haemorrhage and then suturing. ${ }^{8}$

An important but often neglected factor in the technique is that in the infant because the foreskin is adherent to the glans, the skin needs to be separated forcefully initially before it can be excised. This often leads to the glans being denuded of skin with secondary ulceration and superficial infection. A lacrimal probe is used for separation in neonates, allowing inspection of the glans for anomalies-for example, hypospadias or urethral duplication prior to excision of skin. In older children where the foreskin has already become separated, this factor no longer applies.

Circumcision commonly has been done for religious reasons as well as to prevent phimosis, paraphimosis, and balanitis. In addition, there is now evidence that it decreases the risk of urinary infection in neonatal males from seven per 1000 to less than two per 1000.' Also, sexually transmitted diseases (STDs) have been shown to have a 10\% lower rate in circumcised men presenting to an STD clinic in a western country compared to those uncircumcised..$^{10}$ Circumcision may remove an entry site for the HIV/AIDS virus, which can bind to receptors on the inner layer of the foreskin. ${ }^{11}$

In Australia, the commonest reason for requesting circumcision is the father's desire for the baby to look like himself. Since almost $100 \%$ of Australian men older than 45 years of age have been circumcised following second world war experiences of Australian army doctors, a large proportion of society, including doctors, are not familiar with an uncircumcised neonatal male. When fathers see their newborn son, they immediately think that the penis looks different and needs circumcision. It is rare, however, to see a family photo album with father and son shown together completely undressed! Since even in Australian society at present, the incidence of circumcision is significantly less than $30 \%$, it may be more important for the child to be the same as the other children that he will meet at school rather than his own father.

Circumcision provides the definitive treatment for phimosis and recurrent balanitis. ${ }^{12}$ Removal of the foreskin completely prevents any distal scarring and recurrent infection, as there is no longer any pocket for accumulation of urine and debris. Paraphimosis, where the foreskin has been retracted proximal to the glans and then causes venous congestion of the glans, also is prevented by circumcision. Nevertheless, if a child needs admission to the hospital for reduction of paraphimosis with or without an anaesthetic, recurrence is extremely rare. Even small children become embarrassed by this experience, and are able to manage foreskin retraction to prevent this in the future.

Circumcision does reduce the risk of urinary infection in baby boys, but it is unproven whether good perineal hygiene with simply antiseptics would have the same effect. In many places in the USA, the risk of urinary infection is used as a reason for recommending neonatal circumcision. ${ }^{6}$ By contrast, 
in most Australian paediatric hospitals, the risk of urinary infection is used only as an indication for circumcision in children with complex urinary tract anomalies that have been diagnosed antenatally. ${ }^{12}$ Circumcision confirms marginal benefit against sexually transmitted diseases (approximately $10 \%$ advantage $)^{10}$ but whether this justifies circumcision of the entire male population is dubious. Certainly, in subSaharan Africa, circumcision is reported to have significantly greater benefits, particularly in the reduction of HIV, ${ }^{13}$ although not all studies agree with this finding. ${ }^{14}$ Approximately $25 \%$ of the young adult population in South Africa are now thought to be HIV positive. This extremely high incidence suggests major cultural, social, and hygiene differences between the affected population in Africa and many Western countries.

Penile cancer rates can be reduced significantly by circumcision in early life. Circumcision confers a threefold reduction in the risk of cancer over the lifetime of a man. ${ }^{7}$ The very low frequency of penile carcinoma may not, however, justify routine neonatal circumcision. It has been estimated that 300000 circumcisions may be required to prevent one penile cancer per year. ${ }^{7}$ The incidence of penile carcinoma is falling in some Western countries such as Denmark, despite no increase in the number of circumcisions. In fact, circumcision remains a very rare operation in Denmark. It has been suggested that other factors such as the introduction of reticulated hot and cold water to houses throughout Denmark in the last fifty years, is a more likely explanation for the fall in penile carcinoma. ${ }^{15}$

The risks of circumcision, either in the neonatal period or in early childhood, are low. It is estimated that the complication rate in the neonatal period is less than one per cent. ${ }^{6}$ The Gomco clamp and Plastibell device have low complication rates, in the order of $0.2 \% .^{7}$ Nevertheless, the ever present risk of haemorrhagic disease of the newborn, related to inadequate vitamin $\mathrm{K}$ stores in the neonate, should be borne in mind. I have one patient who received oral vitamin $K$ at a time when there was a concern about intramuscular injections being linked to a higher incidence of leukaemia later in childhood. The baby lost more than $200 \mathrm{mls}$ of blood after the operation, and barely escaped death from hypovolaemic shock. After resuscitation, an unrecognised liver disease was found, which accounted for the poor absorption of the oral vitamin $\mathrm{K}$, as this required bile salts in the gut.

\section{ETHICAL ISSUES}

The primary ethical issue for circumcision is that routine circumcision in babies defies standard principles of surgery, as there is no absolute medical indication. ${ }^{16}$ The most fundamental principle of surgery is that no operation should be done if there is no disease, as it cannot be justified if the risk of the procedure is not balanced by the risk of a disease. Even when patients have significant disease, potentially dangerous operations can hardly be justified if their risks are much greater than the disease itself. The problem for routine circumcision is that since there is no disease, no complication whatsoever can be tolerated, since the risks of the procedure are not being balanced against the risks of any present disease. This cost benefit analysis approach exposes routine circumcision as an unnecessary social operation, rather than one justified by medical indications. ${ }^{16}$ Since no disease is present in the neonate, perhaps circumcision could be justified by the possible risks to the patient in the future. This is analogous to the circumstance occurring with immunisation of the population against infectious diseases. The risks of immunisation are justified by the fact that the individual risk to the patient is extremely small, however serious, but the benefits are great, since the incidence of the disease in unimmunised populations may be very high, and may even be a majority of the population. By contrast, the diseases which circumcision is able to prevent are uncommon or even rare, and may be 20-70 years into the future. Furthermore, the potential risk for such diseases as HIV/AIDS may not exist when a population of boys circumcised in 2002 reach adult life. We are not certain at present whether AIDS is going to be an even more widespread disease in the future or whether it will be abolished by some new treatment. Therefore, it would be hard to justify mass circumcision with such a small potential gain. Furthermore, the studies in Denmark suggest indirectly that good hygiene with regular washing may be just as effective at preventing the diseases treated by circumcision. The use of potential diseases in the future as an argument in favour of circumcision can be illustrated by urinary infection in the neonatal period. In the USA, the risk of infection (seven per 1000 ) is used as an indication for circumcision. In our own practice in Australia, however, this is used to offer circumcision to a very small population of boys with known urinary tract anomalies. Since only one per cent of boys suffer a urinary tract infection in the first year of life, most Australian surgeons find it difficult to justify circumcising $100 \%$ of the male population when only one per cent will benefit by reduction in urinary tract infection risk. By contrast, selecting those children at most risk of developing a serious urinary infection for circumcision, takes advantage of the potential benefits but without putting the majority of the population at risk.

There are a number of ethical issues around the social indications for surgery. In post second world war Australia, circumcisions became common in the neonatal period. This carried an unwritten assumption, however, that the next generation of children might grow to be soldiers in the third world war. Hopefully, it will not be necessary to revert to mass circumcision of Australian boys and men so that they can be sent to war in arid environments.

Although fathers often want their boys to be circumcised, whether boys wish to be or not is another matter. It may be only a question of time before adult males who were circumcised in childhood begin legal action against their parents or their doctors for so called mutilation of their bodies without a medical indication or permission. Certainly, I have seen a number of men who had significant surgical complications with circumcision in infancy, leading to subsequently inadequate sexual function. The most serious complication is accidental amputation of the end of the penis or excessive removal of penile shaft skin leading to secondary deformity. In addition, there are many reported cases in the literature of diathermy burn leading to complete necrosis of the penis, as well as accidental amputation. ${ }^{17}$ In many places, such children have had gender reassignment to female because of the loss of the penis. ${ }^{18}$ Every one of these complications is a catastrophe, which could have been avoided by abolition of mass routine circumcision in the neonatal period.

Is circumcision an assault? Surgery would be close to the legal definition of assault if no consent was given and no anaesthetic or analgesia was used. Circumcision done this way is still common place in many parts of the world where five to ten year old boys are held down on the kitchen table by their uncles while another male family member cuts off the foreskin. This is physically cruel and potentially dangerous and must leave major psychological scars. Neonatal circumcision, if done without an anaesthetic, is not far removed from this practice. If doctors agree to perform circumcision on babies and small boys they need to be the advocate for the children and to protect their life and welfare as much as is possible. 


\section{CONCLUSIONS}

Circumcision does offer some health benefits to babies, boys, and men, but only in a small percentage of the population. All surgeons know that circumcision, albeit a simple operation, is still dangerous and carries potential risks to the patient. As surgeons, we need to weigh up these risks carefully against the possible benefits of any surgical intervention. The surgical argument for circumcision of all neonatal males at present is very weak, and with rising public health standards in the developed world, is likely to remain weak. These issues raise numerous ethical questions about surgery used as a social or religious custom, and as a potential preventive measure for possible diseases far into the future.

Correspondence to: Professor J M Hutson, General Surgery, Royal Children's Hospital, Parkville, Victoria 3052, Australia;

hutsonj@cryptic.rch.unimelb.edu.au

Accepted for publication 17 January 2003

\section{REFERENCES}

1 Coran AG. Circumcision in the United States: medical and non-medical attributes. Pediatr Surg Int 1989:4:229-30.

2 Cywes S. Circumcision in South Africa. Pediatr Surg Int 1989;4:233-5.

3 Hofmann V, Kap-Herr S. Circumcision in Germany. Pediatr Surg Int 1989:4:227-8.
4 King PA Caddy GM Cohen $\mathrm{SH}$, et al. Circumcision-maternal attributes. Pediatr Surg Int 1989;4:222-6.

5 Rickwood AMK. Circumcision of boys in England: current practice. Pediatr Surg Int 1989;4:231-2.

6 American Academy of Pediatrics. Circumcision policy statement. Pediatrics 1999;103:686-93.

7 Learman LA. Neonatal circumcision: a dispassionate analysis. Clin Obstet Gynecol 1999; 12:849-59.

8 Langer JC, Coplen DE. Circumcision and pediatric disorders of the penis. Pediatr Clin Nth Amer 1998:45:801-12.

9 To T, Agha M, Dick PT, et al. Cohort study on circumcision of newborn boys and subsequent risk of urinary tract infection. Lancet 1998;353:1813-18.

10 Parker SW, Steward AJ, Wren MN, et al. Circumcision and sexually transmissible disease. Med J Aust 1983;2:288-90.

11 Szabo R, Short RV. How does male circumcision protect against HIV infection? BMJ 2000;320:1592-4.

12 Hutson JM, Woodward AA, Beasley SW, eds. The penis. Jones' clinical paediatric surgery [5th ed]. Melbourne: Blackwell Science Asia, 1999: 194-200

13 Quinn TC, Wawer MJ, Sewankambo N, et al. Viral load and heterosexual transmission of human immunodeficiency virus type 1. N Engl J Med 2000;342:921-9.

14 Van Howe RS. Circumcision and HIV infection: review of the literature and meta-analysis. Int J STD AIDS 1999;10:8-16.

15 Frisch M, Frûs S, Kịlar SK, et al. Falling incidence of penis cancer in an uncircumcised population (Denmark 1943-90). BMJ 1995;311:1471.

16 American Academy of Pediatrics, Committee on Fetus and Newborn. Standards and recommendations for hospital care of newborn infants [5th ed]. Evanston, IL: American Academy of Pediatrics, 1971

17 Coskunfirat OK, Sayilkan S, Velidedeoglu H. Glans and penile skin amputation as a complication of circumcision. Am Plastic Surg 1994;43:457. 18 Money J. Ablatio penis: normal male infant sex reassigned as a girl. Arch Sex Behav 1975;4:65-70. 